\title{
1 Prevalence and Outcome of Cardio-Embolic Stroke Patients Admitted at Referral Neurology Hospital in Bangladesh
}

S K Jakaria Been Sayeed ${ }^{19 *}$, A K M Mahmudul Haque ${ }^{19}$, Md. Moniruzzaman ${ }^{1 \&}$, Reaz Mahmud ${ }^{2 \uparrow}$, Md. Abdullah Yusuf ${ }^{1 \&}$, Subir Chandra Das ${ }^{1 \&}$, Mohammad Bazlur Rashid ${ }^{1 \&}$, Sabrina Rahman ${ }^{2 \&}$, Abu Nayeem ${ }^{1 \&}$, A K M Humayon Kabir ${ }^{2 \&}$, M S Jahirul Haque Chowdhury 1\&, Md. Mujibur Rahman ${ }^{3 \uparrow}$.

1 Stroke Unit, National Institute of Neurosciences and Hospital, Dhaka, Bangladesh

2 Medicine Departments, Dhaka Medical College Hospital, Dhaka, Bangladesh

*Corresponding author

\section{Dr. S. K. Jakaria Been Sayeed}

MBBS, MACP (USA), MRCP (Medicine- UK), MRCP (Medicine- Edinburgh)

"These authors contributed equally to this work.

\&These authors contributed equally to this work.

\section{Acknowledgments}

27 We are grateful to our patients and their relatives who gave informed consent for participation in this study. Special thanks to Professor Quazi Deen Mohammad Sir, director of NINS, for his continuous support. Moreover, we are grateful to radiology department for their enormous help regarding radioimaging of the brain \& neck vessels. 
32 Abstract

33 Background

34 Stroke is the second leading cause of mortality worldwide; where the majority of stroke is

35 ischemic. Among ischemic stroke, cardio-embolic has both higher severity and mortality.

\section{Objective}

37 To find out clinical outcomes and determine predictors of mortality related to cardio-embolic stroke.

\section{Methodology}

This prospective cohort study was conducted among patients of acute ischemic stroke of cardiac origin admitted at the National Institute of Neurosciences and Hospital, Bangladesh from $1^{\text {st }}$ October 2020 to 30 September, 2021. Patients were kept under follow-up to 90 days from

43 discharge.

\section{$44 \quad$ Results}

A total of 689 ischemic stroke patients were screened, 156 had confirmed Cardio-embolic stroke. So, the frequency of cardio-embolic stroke was $22.64 \%$. Male to female ratio was $1.3: 1$, mean age of 63 years. Hypertension 119 (76.3\%), atrial fibrillation 107 (68.6\%), and IHD 40 (25.6\%) were most common comorbidities. Interestingly, we found only $23(14.7 \%)$ patients with chronic rheumatic heart diseases. NIH Stroke scale score (median, IQR) during admission was 13 [719]. Overall mortality was 47 (29.9\%), among them 30 (19.2\%) died within 48 hours of hospital admission while 17 (10.9\%) within 90 days of hospital discharge. Modified Rankin score at 90 days was 2 [ $\min 0, \max 5]$ those who survived. Cumulative incidence of recurrent stroke was 9 (7.1\%) and incidence of anticoagulant induced hemorrhage were 5 (3.2\%) among them. Risk factors associated with mortality (odds ratio, [95\% CI], p value) were acute myocardial infarction $(1.6$ [1.14 - 2.52] , 0.04), raised Troponin (1.89 [1.16-2.99], 0.01), reduced ejection fraction (3.38 [2.17-5.27], <0.001), hypotension (3.12 [2.07 - 4.68], < 0.001), chronic kidney disease (1.82 [1.06 - 3.10], 0.04), raised Creatinine (2.41 [1.52 -3.84], 0.01), raised blood sugar (1.82 [1.14 - 2.89], 0.02), severe stroke (9.45 [3.57 - 25.03], <0.001), large infarct (53.67 [7.59 - 379.47], < 0.001), hemorrhagic transformation $(4.43[2.89-6.84],<0.001)$ and aspiration pneumonia (1.9 [1.28-2.39], 0.01) .

\section{Conclusion}

63 Overall frequency, severity, functional disability, and mortality in cardio-embolic stroke are

64 higher. Acute myocardial infarction, severe stroke, presence of hyperglycemia, hypotension, 65 renal impairment, low ejection fraction, large infarct, hemorrhagic transformations, and 
aspiration pneumonia are both clinically and statistically significantly associated with mortality in cardio-embolic stroke.

Key words:

Cardio-embolic stroke, frequency, outcomes, predictors of mortality

\section{Abbreviations}

AF- Atrial fibrillation, COPD- Chronic Obstructive Pulmonary Disease, CRHD- Chronic Rheumatic Heart Disease, ECG- Electrocardiogram, IHD- Ischemic Heart Disease, ICH- Intra Cerebral Hemorrhage, MRS- Modified Rankin Score, MI- Myocardial Infarction, NIHSSNational Institute of Health Stroke Scale, TIA- Transient Ischemic Attack, TSH- Thyroid Stimulating Hormone.

\section{Introduction}

Each year twenty-six million people worldwide experience a stroke and it is the second-leading cause of mortality and a leading cause of long-term disability [1]. One-third of strokes represent intracerebral or subarachnoid hemorrhage, whereas two-thirds represent cerebral ischemia [1]. The reported prevalence of stroke in Bangladesh is $0.3-1 \%[2,3]$. Approximately one in four ischemic strokes is of cardio-embolic origin [4]. Atherosclerosis of the cerebral circulation, occlusion of cerebral small vessels, and cardiac embolism are the major causes of ischemic stroke [5]. According to Stroke Data Bank and Registries divided the potential cardiac causes of the stroke into strong sources (prosthetic valves, atrial fibrillation, sick-sinus syndrome, ventricular aneurysm, akinetic segments, mural thrombi, cardiomyopathy and diffuse ventricular hypokinesia) and weak sources (myocardial infarct in earlier months, aortic and mitral stenosis, aortic, and mitral regurgitation, congestive heart failure, mitral valve prolapse, mitral annulus calcification, and hypokinetic ventricular segments) [6, 7]. Cryptogenic stroke accounts for 25\% of all ischemic strokes, the majority of which is likely to be of embolic origin [8]. Cardioembolic stroke has been increasing in number not only in the developed country but also in low to middle-income countries whereas the overall incidence of stroke is decreasing due to adequate treatment and prevention strategies against hypertension, dyslipidemia [9, 10, and 11]. In Bangladesh, chronic rheumatic heart disease is one of the common causes of cardio-embolic stroke, prevalence of rheumatic heart disease is 0.9 per 1000 [12]. The risk of recurrence in cardio-embolic stroke, is highest (around 10\%) in the first weeks after the stroke that drops to $5 \%$ in the following 12 months, however, the risk of early embolic recurrence varies between 1 
to $10 \%$ [13]. Cardio-embolic stroke is known to cause more severe stroke and higher mortality [14] than other stroke subtypes. However, in Bangladesh prevalence of cardio-embolic stroke is not adequately evaluated, there is a lack of sufficient information regarding clinical \& laboratory characteristics. Moreover, information regarding neurological and cardiac outcomes is still not

102 known. Nevertheless, effect \& outcome of anticoagulant therapy especially in myocardial infarction, rheumatic heart disease, or atrial fibrillation with ischemic stroke in our country still inadequately described. For this reason, we have conducted this prospective study to describe hospital prevalence, clinical and anticoagulant treatment outcomes among patients who were management of this group of patients.

\section{Materials and Methods}

\section{Study Settings and Populations}

112 This was a prospective study, conducted at the National Institute of Neurosciences, the largest 113 neurology referral hospital in Bangladesh. All acute ischemic stroke patients due to cardio114 embolism admitted for the first time in NINS were enrolled [Figure 1].

Excluded

Not meeting the inclusion criteria

Declined to participate 


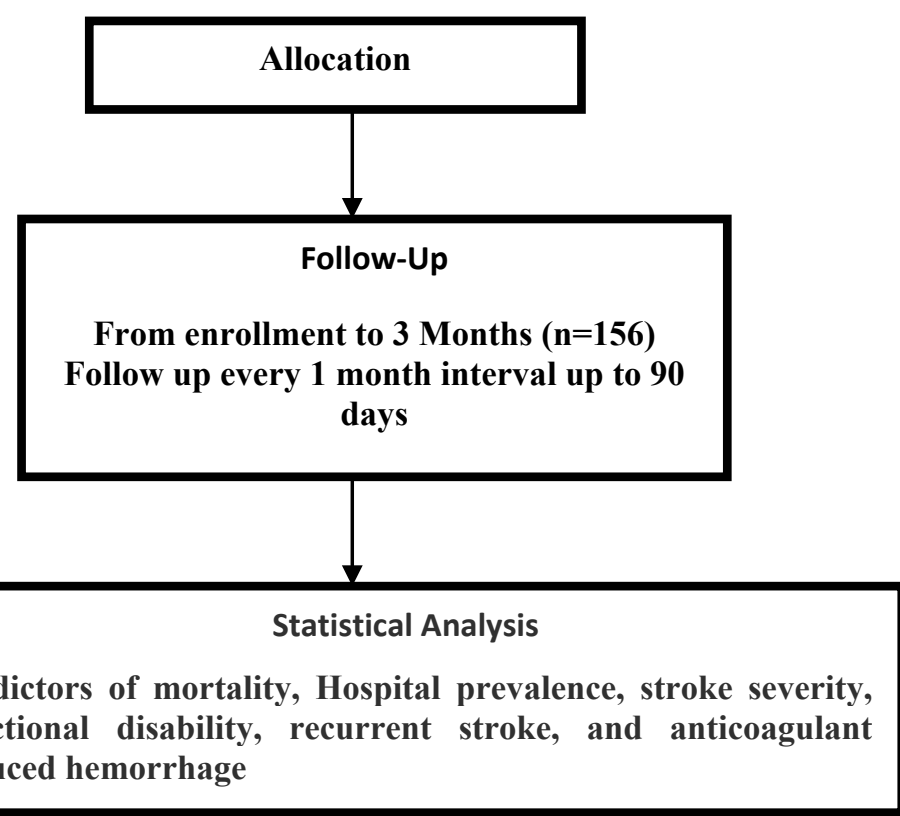

Figure 1: Schematic flow chart of research work

\section{Inclusion criteria:}

Patients, more than 18 years of age with acute ischemic stroke diagnosed by CT or MRI within 1 week of index events due to cardiac causes diagnosed by electrocardiogram, echocardiography, (Arrhythmia, Acute MI, CRHD, Left ventricular aneurysm, prosthetic heart valve, atrial myxoma or any thrombus or vegetation in the cardiac chamber or valve surface) was included in the study.

\section{Exclusion criteria:}

Patients with intracranial hemorrhage or infection or tumor, transient ischemic attack, ischemic stroke due to neck vessels thrombus/ disease, severe organ dysfunction (renal and liver Injury), and other causes of cerebral infarction (Coagulopathy, Vasculitis, and tumor) were excluded.

\section{Outcomes Measure}

Primary outcome was to determine predictors of mortality at 90 days after the index event. Secondary outcomes were assessing functional status by modified ranking scale score (mRS), recurrent stroke (ischemic or hemorrhagic) at 90 days after the index event. Moreover, we also determined the hospital frequency, measured stroke severity by using NIHSS (National Institute of Health Stroke Score) during admission and before discharge, and anticoagulant induced hemorrhage especially intracranial hemorrhage at 90 days. 


\section{Investigations \& Follow up}

For, each patient's base line investigations like CBC, Urine R/E, Creatinine, SGPT, RBS, HbA1C, Electrolyte with special investigations like (Coagulation profile, D-dimer, Troponin I,

163 Fasting lipid profile, TSH, ANA, ANCA if needed) were done. 12 lead ECG, 24 hours halter (if applicable), Echocardiography (2D, M mode, color Doppler), CT/ MR angiogram of Brain and Neck vessels were done where necessary. Here, all investigations were done at NINS. We kept discharged patients under regular follow-up for up to 90 days from the index event. After discharge $1^{\text {st }}$ follow-up was given 1 month from index event, thereafter $2^{\text {nd }}$ follow-up 1 month from $1^{\text {st }}$ follow-up, again $3^{\text {rd }}$ follow-up was given 1 month from $2^{\text {nd }}$ follow-up. As the COVID situation is ongoing we had maintained follow-up using social media like what's app, messenger, imo and viber (video conference) whatever available. Two trained doctors were allocated for data collection, follow-up schedule maintenance. Those who suffered a further stroke were admitted in the same institute for evaluation and management.

\section{Statistical Analysis}

175 As cardio-embolic stroke prevalence in Bangladesh is 4.9\% according to Bhowmik NB et al. [15]. 176 Therefore, we assume 72 will be the size according to the prevalence equation. However, we 177 enrolled 156 cardio-embolic stroke patients among 689 acute ischemic stroke patients as per 178 inclusion criteria. The Sampling technique was purposive \& consecutive. All data had been analyzed in SPSS 24 version. Continuous variable had been expressed with number, mean and standard deviation (SD) while value with skewed deviation expressed as IQR (Interquartile Range). Comparison between groups (Group A- alive, Group B- death) with mortality \& functional outcome were analyzed by Pearson chi-square test for categorical variable. For continuous variable independent student's t (normally distributed) or Mann Whitney U test for skewed data were applied. For assessing predictors of mortality, binary logistic regression analysis was done. Predictors were expressed with odds ratio with 95\% confidence interval which was adjusted with age, sex.

\section{Ethical Issues}


This study was conducted in full conformance with the ICH E6 guideline for Good Clinical Practice (ICH-GCP) and the principles of the Declaration of Helsinki and ethical clearance from the respective institutional review boards [ERC No- NINS 24-120-21 ].

\section{Results}

A total of 689 ischemic stroke patients were screened, 156 had confirmed Cardio-embolic stroke. So, the frequency of cardio-embolic stroke in NINS is $22.64 \%$. Overall, the male to female ratio was 1.3:1, mean age of $63( \pm 15)$ years. The most commonly affected age group is 61-70, 45 (28.8\%). Sixty-six (42.3\%), 17 (12.1\%) used to smoke \& drinks alcohol accordingly. Hypertension 119 (76.3\%), Atrial fibrillation 107 (68.6\%) and ischemic heart disease 61 (39.1\%) were most common risk factors. However, it is worthwhile to mention $56(35.9 \%)$ had acute myocardial infarction as important risk factors. Interestingly, we found only $23(14.7 \%)$ patients with chronic rheumatic heart diseases, and 11 (7.5\%) had hyperthyroidism. Duration of hospital stay was 7 days (minimum 3, maximum 17) in group A while in group B it was 2 days (minimum 1 and maximum 21 days). For Group A, NIH stroke scoring during admission was 9 (minimum 2, maximum 26), while on discharge it was 4 (minimum 0, maximum 11). For Group B, NIH stroke scoring during admission was 21 (minimum 7, maximum 29), while on discharge it was 8 (minimum 4, maximum 11). Most of the cardio-embolic stroke had moderate severity 56 $(35.9 \%)$ in Group A while for Group B it was severe 25 (16.1\%) [Table 1].

\begin{tabular}{|l|r|r|r|}
\hline Characteristics & \multicolumn{3}{|c|}{ Results } \\
\hline & $\begin{array}{c}\text { Group A- Alive } \\
(\mathbf{1 0 9 )}\end{array}$ & $\begin{array}{c}\text { Group B- Death } \\
\text { (47) }\end{array}$ & Total (156) \\
\hline Age (Mean, SD) & $61.7 \pm 16.6$ & $66.7 \pm 13.8$ & $63.2 \pm 15.9$ \\
\hline Age Group (Years, frequency, & & & \\
percentage) & $2(1.3)$ & $1(0.6)$ & $3(1.9)$ \\
$\mathbf{2 1 - 3 0}$ & $12(7.7)$ & $1(0.6)$ & $13(8.3)$ \\
$31-40$ & $12(7.7)$ & $1(0.6)$ & $13(8.3)$ \\
$41-50$ & $26(16.7)$ & $13(8.3)$ & $39(25)$ \\
$51-60$ & $29(18.6)$ & $16(10.2)$ & $45(28.8)$ \\
$61-70$ & $16(10.2)$ & $8(5.1)$ & $24(15.3)$ \\
$71-80$ & $8(5.1)$ & $5(3.2)$ & $13(8.3)$ \\
$81-90$ & $4(2.6)$ & $2(1.3)$ & $6(3.8)$ \\
$91-100$ & & & \\
\hline Sex & $57(36.5)$ & $30(19.2)$ & $87(55.8)$ \\
Male & $52(33.3)$ & $17(10.9)$ & $69(44.2)$ \\
Female & & & \\
\hline
\end{tabular}


medRxiv preprint doi: https://doi.org/10.1101/2022.02.16.22271069; this version posted February 21, 2022. The copyright holder for this preprint (which was not certified by peer review) is the author/funder, who has granted medRxiv a license to display the preprint in perpetuity.

It is made available under a CC-BY 4.0 International license .

\begin{tabular}{|c|c|c|c|}
\hline Smoker & $45(28.8)$ & $21(13.5)$ & $66(42.3)$ \\
\hline Alcoholic & $12(7.7)$ & $5(3.2)$ & $17(10.9)$ \\
\hline $\begin{array}{l}\text { Family H/O Stroke or Heart } \\
\text { Disease }\end{array}$ & $59(37.8)$ & $20(12.8)$ & $79(50.6)$ \\
\hline $\begin{array}{l}\text { Co-morbidities( frequency, } \\
\text { percentage) } \\
\text { Hypertension } \\
\text { Atrial Fibrillation } \\
\text { Dyslipidemia } \\
\text { Acute Myocardial Infarction } \\
\text { Diabetes } \\
\text { Ischemic Heart Disease } \\
\text { Chronic Rheumatic Heart Disease } \\
\text { Chronic Kidney Disease } \\
\text { Hyperthyroidism } \\
\text { Asthma } \\
\text { COPD } \\
\text { Prosthetic Heart Valve }\end{array}$ & $\begin{array}{r}79(50.6) \\
78(50) \\
30(19.2) \\
34(21.8) \\
39(25) \\
40(25.6) \\
17(10.9) \\
9(5.8) \\
11(7.5) \\
4(2.6) \\
3(1.9) \\
3(1.9)\end{array}$ & $\begin{array}{r}40(25.6) \\
29(18.6) \\
13(8.3) \\
22(14.1) \\
24(15.4) \\
21(13.5) \\
6(3.8) \\
9(5.8) \\
0 \\
0 \\
1(0.7) \\
1(0.7)\end{array}$ & $\begin{array}{r}119(76.3) \\
107(68.6) \\
43(27.5) \\
56(35.9) \\
63(40.4) \\
61(39.1) \\
23(14.7) \\
18(11.6) \\
11(7.5) \\
8(5.1) \\
4(2.6) \\
4(2.6)\end{array}$ \\
\hline $\begin{array}{l}\text { Hospital stay, } \\
{[\mathrm{IQR}]}\end{array}$ & $7[\min 3, \max 17]$ & $2[\min 1, \max 21]$ & $7[5-9]$ \\
\hline $\begin{array}{l}\text { NIHSS Score on admission, Median } \\
\text { [IQR] }\end{array}$ & $9[\min 2, \max 26]$ & $21[\min 7, \max 29]$ & $13[7-19]$ \\
\hline $\begin{array}{l}\text { NIHSS Score on discharge, Median } \\
\text { [IQR] }\end{array}$ & $4[\min 0, \max 11]$ & $8[\min 4, \max 11]$ & $5[3-7]$ \\
\hline $\begin{array}{l}\text { NIHSS Severity } \\
\text { Mild } \\
\text { Moderate } \\
\text { Moderate to severe } \\
\text { Severe }\end{array}$ & $\begin{array}{r}13(8.3) \\
56(35.9) \\
27(17.3) \\
13(8.3)\end{array}$ & $\begin{array}{r}0 \\
4(2.6) \\
18(11.5) \\
25(16.1)\end{array}$ & $\begin{array}{r}13(8.3) \\
60(38.5) \\
45(28.8) \\
38(24.4)\end{array}$ \\
\hline On Anticoagulant therapy & $106(67.9)$ & $37(23.7)$ & $143(91.7)$ \\
\hline On Beta Blocker & $103(66)$ & $33(21.1)$ & $136(87.1)$ \\
\hline
\end{tabular}

Table 1. Demographic Characteristics and severity of Cardio-embolic Patients $(n=156)$

211 NIHSS- National Institute of Health Stroke Severity Score

212 COPD- Chronic obstructive lung disease

214 Regarding ECG observation, atrial fibrillation was seen in 107 (68.6\%) followed by acute 215 myocardial infarction 56 (35.9\%). However, in echocardiogram ejection fraction was reduced in $21639(24.8 \%)$ although wall motion hypokinesia present in $47(30.1 \%)$ [Table 2].

\begin{tabular}{|l|r|}
\hline \multicolumn{1}{|c|}{ Findings } & \multicolumn{1}{|c|}{ Frequency (\%) } \\
\hline Atrial Fibrillation & $107(68.6)$ \\
\hline Left Ventricular Hypertrophy & $26(16.7)$ \\
\hline
\end{tabular}




\begin{tabular}{|l|r|}
\hline STEMI & $33(21.2)$ \\
\hline IHD & $31(12.1)$ \\
\hline NSTEMI & $23(19.9)$ \\
\hline Variable AV Block & $9(5.7)$ \\
\hline Atrial Flutter & $5(3.2)$ \\
\hline Echocardiography & \\
& $113(72.4)$ \\
Rhythm Abnormality & $31(19.8)$ \\
Concentric Hypertrophy & $23(14.7)$ \\
Valvular Heart disease & $4(2.6)$ \\
Valve Replacement & $47(30.1)$ \\
Wall Hypokinesia & $39(24.8)$ \\
Reduced EF & $116(75.2)$ \\
Preserved EF & \\
& \\
\hline
\end{tabular}

STEMI- ST Elevated Myocardial Infarction, NSTEMI- Non ST Elevated Myocardial Infarction, IHD- Ischemic Heart Disease, AV- Atrio-Ventricular, EF- Ejection Fraction.

Table 2: Cardiac Abnormality observed in Electrocardiography and Echocardiography $(n=156)$

Most commonly involved lobe in cardio-embolic stroke was parietal 50 (32.1\%) but interestingly frequently involved vascular territory $116(74.4 \%)$ [Table 3$].$

\begin{tabular}{|l|r|}
\hline \multicolumn{1}{|c|}{ Trait } & Frequency (\%) \\
\hline Lobe & \\
Parietal & $50(32.1)$ \\
Frontal & $19(12.2)$ \\
Temporal & $2(1.3)$ \\
Occipital & $3(1.9)$ \\
Cerebellar & $11(3.6)$ \\
Fronto-parietal & $42(7.1)$ \\
Parieto-temporal & $10(6.4)$ \\
Parieto-Occipital & $2(1.3)$ \\
Multiple & $17(10.8)$ \\
\hline Vascular Territory & \\
\hline
\end{tabular}


90 days clinical outcome was variable as modified Rankin score (disability scoring) was 3 (minimum 0, maximum 5), had some symptoms 37 (29.1\%) and minor disability 31 (24.4\%) among 109 patients. Hemorrhagic infarct occurred in 29 (18.5\%) patients; among them 5 (3.2\%) had developed after starting anticoagulant. Only 8 (7.3\%) patients developed recurrent ischemic stroke even though on anticoagulant $\&$ beta blocker while only $7(4.5 \%)$ suffered hemorrhagic stroke. Overall mortality was 47 (29.9\%), among them $30(19.2 \%)$ died on 24-48 hours of hospital admission while 17 (10.9\%) within 90 days of hospital discharge [Table 4].

\begin{tabular}{|l|r|r|r|}
\hline \multicolumn{1}{|c|}{ Outcomes } & & \multicolumn{1}{|c|}{ Results } \\
\hline MRS ( Modified Rankin & Group A- alive & \multicolumn{1}{|c|}{ Group B-death } & \\
Score) Median [IQR] & 2 [min 0, max 5] & 6 & \\
At 3 months & $3[2-3]$ & & \\
\hline MRS Severity at 90 days & $16(12.6)$ & 0 & $16(12.6)$ \\
No limitations & $37(29.1)$ & 0 & $37(29.1)$ \\
Some Symptoms & $31(24.4)$ & 0 & $31(24.4)$ \\
Minor disability & $21(16.5)$ & 0 & $21(16.5)$ \\
Moderate disability & $5(3.9)$ & 0 & $5(3.9)$ \\
Severe disability & & $17(13.4)$ & $17(13.4)$ \\
Death & $6(3.8)$ & $23(14.7)$ & $29(18.5)$ \\
& $2(1.3)$ & $3(1.9)$ & $5(3.2)$ \\
\hline Hemorrhagic Infarct & & & \\
Anticoagulant induced & & & $7(7.3)$ \\
hemorrrhage & & & $7(4.5)$ \\
\hline Recurrent Stroke within 90 & $6(3.8)$ & $4(2.6)$ & $47(29.9)$ \\
days & $3(1.9)$ & & \\
Ischemic & & & \\
Hemorrhagic & & & \\
\hline Death & & & \\
\hline
\end{tabular}


Risk factors associated with mortality were acute myocardial infarction OR 1.6 [1.14 - 2.52] $\mathrm{p}$ $=0.04$, severe stroke OR 9.45 [3.57 - 25.03], $\mathrm{p}<0.001$, hypotension OR 3.12 [2.07 - 4.68], p <

0.001, raised Troponin-I OR 1.89 [1.16-2.99], $\mathbf{p}<0.01$, raised blood sugar OR 1.82 [1.14 - 2.89], $\mathbf{p}<$ 0.02, raised Creatinine OR 2.41 [1.52 -3.84] $\mathbf{p}<\mathbf{0 . 0 1}$, low ejection fraction OR 3.38 [2.17-5.27] $\mathbf{p}<$ 0.001, large infarct 53.67 [7.59 - 379.47] p < 0.001, hemorrhagic infarction OR $4.43[2.89-6.84] p<$ 0.001 and aspiration pneumonia OR 1.9 [1.28-2.39] $\mathrm{p}=0.01$. [Table5].

\begin{tabular}{|c|c|c|}
\hline Risk Factors & OR [ $95 \% \mathrm{Cl}$ ] & P value \\
\hline Age & $0.98[0.95-1.01]$ & 0.08 \\
\hline Sex & $1.40[0.85-2.32]$ & 0.25 \\
\hline Smoker & $1.1[0.68-1.77]$ & 0.83 \\
\hline Diabetes & $1.50[0.96-2.48]$ & 0.11 \\
\hline Hypertension & $1.7[0.87-3.63]$ & 0.14 \\
\hline Ischemic heart disease & $1.26[0.78-2.02]$ & 0.45 \\
\hline Chronic kidney disease & $1.82[1.06-3.10]$ & 0.04 \\
\hline Chronic rheumatic heart Disease & $0.85[0.41-1.76]$ & 0.83 \\
\hline Atrial fibrillation & $0.74[0.46-1.45]$ & 0.30 \\
\hline Acute Myocardial infarction & $1.6[1.14-2.52]$ & 0.04 \\
\hline Raised Troponin & 1.89 [1.16-2.99] & 0.01 \\
\hline Raised Blood Sugar & $1.82[1.14-2.89]$ & 0.02 \\
\hline Raised Creatinine & $2.41[1.52-3.84]$ & 0.001 \\
\hline Hypotension & $3.12[2.07-4.68]$ & $<0.001$ \\
\hline Severe Stroke & $9.45[3.57-25.03]$ & $<0.001$ \\
\hline Low Ejection fraction & $3.38[2.17-5.27]$ & $<0.001$ \\
\hline Large Infarct & $53.67[7.59-379.47]$ & $<0.001$ \\
\hline Hemorrhagic Infarction & $4.43[2.89-6.84]$ & $<0.001$ \\
\hline Aspiration Pneumonia & $1.9[1.28-2.39]$ & 0.01 \\
\hline
\end{tabular}


Cardio-embolic stroke prevalence has been increasing for the last few decades especially among the elderly. Approximately one in four ischemic strokes is of cardio-embolic origin [3], exerting a profound societal impact, association with greater disability, higher mortality rates, and higher treatment costs as compared to patients with strokes from other causes $[16,17]$. To the best of our knowledge, this is the $1^{\text {st }}$ prospective cohort study that evaluates hospital frequency, clinical outcome, and risk factors determination for mortality among cardio-embolic stroke patients admitted in the largest neurological hospital of Bangladesh. Bhowmik NB et al. described hospital frequency of cardio-embolic stroke as $4.9 \%$ but failed to confirm in $17.2 \%$ [16], those who were suspected cases for cardio-embolic stroke. Manorenj S et al. [18] observed 11.6\% in a prospective study from south India. However, we have observed frequency is $22.05 \%$, it's obvious there is a significant difference. As we have large sample size, ambulatory 24 hour ECG facility, and portable echocardiogram that helped us for better identification. The prevalence of cardio-embolic stroke in Bangladesh is compatible to the western report of $15-30 \%$ [19]. In our cohort study risk factors profile demonstrated hypertension followed by atrial fibrillation are the predominant factors associated with cardio-embolic stroke, very similar to the observation of Manorenj S et al. [18] but different from Henninger $\mathrm{N}$ et al [20] who found atrial fibrillation as the predominant factor. Hypertension is certainly the most common condition affecting humans and one in every five Bangladeshi suffers from high blood pressure according to Rahman M et al. [21] from Bangladesh. Cardiac involvement usually occurs in patients with hypertension can lead to the development of atrial fibrillation \& stroke [22]. Recent myocardial infarction with left ventricular dysfunction causing aneurysm or thrombus in the heart that can cause cardio-embolic stroke [23]. We do have a similar observation as (28.6\%) of our patients suffered acute MI, a majority had low ejection fraction in (23.5\%) before the development of stroke, like MacDougall NJJ et al [23]. To identify ischemic stroke was due to cardio-embolic or thromboembolic we went for an MR angiogram of neck vessels and brain in almost every suspicious cases along with an MRI of Brain. Most of the embolic stroke in present cohort involved predominantly left middle cerebral artery with the parietal lobe of the brain which means the source of embolus was the heart. Manorenj S et al. [18], Henninger N et al. [20] \& Hart RG [24] had also observed similar vascular \& site of brain involvement. Cardiac emboli arising from the cardiac chambers are often large and cause severe stroke, disability, and mortality. They also have high chances of early as well as late embolic recurrences. Hence, early identification of cardio-embolic stroke is 
crucial for planning the appropriate treatment mode (anticoagulation) and prevention strategies. In our cohort, the majority (45.7\%) suffered moderate to severe stroke according to NIHSS grading. Twenty-four (17.1\%) patients out of 40 died within 24 hours of hospital admission. Probably large infarct with severe stroke with acute STEMI (ST elevated myocardial infarction) with low ejection fraction $(\mathrm{EF}<40 \%)$ and delayed referral to specialized stroke unit were the responsible factors behind in-hospital mortality. It is worthwhile to mention that $24(17.1 \%)$ patient's died during hospital stay where Arboix A \& Alió J. mentioned in-hospital mortality in their study was 27.3\% [25]. Modified rankin score (MRS $\geq 3$ ) at 90 days was not favorable for those who are alive because most of them have minor to moderate disability. Henninger $\mathrm{N}$ et al. [20] in their study also observed an unfavorable 90-day functional status among cardio-embolic patients.

Occluded intracranial vessels with early recanalization and ischemic infarct with hemorrhagic transformations are suggestive of a cardiac-embolic stroke [26]. We observed $21.4 \%$ cases of hemorrhagic infarction mostly due to the disease process. However, we also observed anticoagulant-induced hemorrhage in the brain especially those who were on warfarin, had chronic kidney disease, high blood pressure, atrial fibrillation, elderly and labile INR. Hart RG [27] also mentioned those risk factors causing intracerebral hemorrhage in patients who were on warfarin. Nevertheless, even after adequate anticoagulation, few of our patients suffered a recurrent ischemic stroke. Seiffge DJ et al. [28] described during follow-up of 6128 patient's of acute ischemic stroke with atrial fibrillation on anticoagulant therapy, 289 patients had a further acute ischemic stroke (4.7\% per year), 90 patients had ICH (1.5\% per year), and 624 patients died (10.2\% per year) while on an anticoagulant. Anticoagulation therapy is stills not enough to prevent recurrent ischemic stroke. That's why further study is needed to find out the pharmacodynamics of different anticoagulants among those who are on an anticoagulant. One of the major concerns of cardio-embolic stroke is long-term mortality. We analyzed those patients who died in our study duration through binary logistic regression model to find out predictors of mortality. We have found hypotension, acute myocardial infarction, low ejection fraction; large infarct, severe stroke, and aspiration pneumonia were significantly associated with mortality, similar to Byun JI et al. [16], Henninger N et al. [20], MacDougall NJJ et al [23]. So, cardio- 
embolic stroke patients need specialized units run by a multidisciplinary team including intervention facilities and close monitoring to reduce mortality.

Our study has several strengths, like study design was the prospective cohort, having adequate sample size, patients having an ischemic stroke for the first time were included and conducted in a center equipped with adequate investigation facilities, and dedicated team who kept all the patients under regular follow up even in Covid pandemic. However, we do have some limitations. It is a single center study; did not evaluate adequately who suffered a recurrent ischemic stroke within 90 days of hospital discharge although prescribed medications were appropriate. Moreover, we showed some factors that were associated with poor outcome (mortality) through binary logistic regression model but further large-scale study is needed to find out a causal relationship between those factors with mortality.

\section{Conclusion}

To the best of our knowledge, our study is the first-ever work done in Bangladesh to determine the frequency of cardio-embolic stroke in a specialized center, narrated clinical outcomes, determined predictors of mortality, and frequency of anticoagulant induced intracerebral hemorrhage among those stroke patients that most clinician fears off. As mortality in cardioembolic stroke is high so early identification, timely referral to a specialized hospital, managing those risk factors related to mortality by a multidisciplinary team should be considered as a corner stone in cardio-embolic stroke management. We believe that it is going to modify not only standard protocol in the different centers but also health policy related to cardio-embolic stroke.

\section{Acknowledgments}

We are grateful to our patients and their relatives who gave informed consent for participation in this study. Special thanks to Professor Quazi Deen Mohammad Sir, director of NINS, for his continuous support. Moreover, we are grateful to radiology department for their enormous help regarding radioimaging of the brain \& neck vessels.

\section{References}

1. Krishnamurthi RV, Feigin VL, Forouzanfar MH, et al. Global Burden of Diseases IRFS and Group GBDSE. Global and regional burden of first-ever ischaemic and haemorrhagic 
stroke during 1990-2010: findings from the Global Burden of Disease Study 2010. Lancet Glob Health. 2013;1:e259-e281

2. Islam MN, Moniruzzaman M, Khalil MI, et al. Burden of stroke in Bangladesh. Int J Stroke. 2013; 8(3):211-213. doi:10.1111/j.1747-4949.2012.00885.x

3. Chowdhury MZI, Haque MA, Farhana Z, et al. Prevalence of cardiovascular disease among Bangladeshi adult population: a systematic review and meta-analysis of the studies. Vasc Health Risk Manag. 2018; 14: 165-181. Published 2018 Aug 21. doi:10.2147/VHRM.S166111

4. Díaz Guzmán J. Ictus cardioembólico: epidemiología [Cardioembolic stroke: epidemiology]. Neurologia. 2012; 27 Suppl 1:4-9. doi:10.1016/S0213-4853(12)70002-6

5. Adams HP Jr, Bendixen BH, Kappelle LJ, et al. Classification of subtype of acute ischemic stroke. Definitions for use in a multicenter clinical trial. TOAST. Trial of Org 10172 in Acute Stroke Treatment. Stroke. 1993; 24:35-41.

6. Hier D.B. (1995) Stroke Data Banks and Stroke Registries. In: Caplan L.R. (eds) Brain Ischemia. Springer, London. https://doi.org/10.1007/978-1-4471-2073-5_36

7. Kamel H, Healey JS. Cardioembolic Stroke. Circ Res. 2017; 120(3):514-526. doi:10.1161/CIRCRESAHA.116.308407

8. Maier IL, Schregel K, Karch A, et al. Association between Embolic Stroke Patterns, ESUS Etiology, and New Diagnosis of Atrial Fibrillation: A Secondary Data Analysis of the Find-AF Trial. Stroke Res Treat. 2017Apr:1-6.

9. Bogiatzi C, Hackam DG, McLeod AI, Spence JD. Secular trends in ischemic stroke subtypes and stroke risk factors. Stroke. 2014; 45: 3208-3213.

10. Yiin GS, Howard DP, Paul NL, et al. Oxford Vascular Study. Age-specific incidence, outcome, cost, and projected future burden of atrial fibrillation-related embolic vascular events: a population- based study. Circulation. 2014; 130:1236-1244.

11. Chugh SS, Havmoeller R, Narayanan K, et al. Worldwide epidemiology of atrial fibrillation: a Global Burden of Disease 2010 Study. Circulation. 2014; 129:837-847.

12. Islam AK, Majumder AA. Rheumatic fever and rheumatic heart disease in Bangladesh: A review. Indian Heart J. 2016; 68(1):88-98. doi:10.1016/j.ihj.2015.07.039

13. Lovett JK, Coull AK, Rothwell PM. Early risk of recurrence by subtype of ischemic stroke in population-based incidence studies. Neurology. 2004 Feb; 62:569-73. 
14. Stead LG, Gilmore RM, Bellolio MF, et al. (2011) Cardioembolic but not other stroke subtypes predict mortality independent of stroke severity at presentation. Stroke Res Treat 2011: 281496

15. Bhowmik NB, Abbas A, Saifuddin M, et al. Ischemic Strokes: Observations from a Hospital Based Stroke Registry in Bangladesh. Stroke Res Treat. 2016;2016:5610797. doi:10.1155/2016/5610797

16. Byun JI, Jung KH, Kim YD, Kim JM, Roh JK (2014) Cardiac Function and Outcome in Patients with Cardio-Embolic Stroke. PLOS ONE 9(4): e95277. https://doi.org/10.1371/journal.pone.0095277

17. January CT, Wann LS, Alpert JS, et al. 2014 AHA/ACC/HRS guideline for the management of patients with atrial fibrillation: a report of the American College of Cardiology/American Heart Association Task Force on Practice Guidelines and the Heart Rhythm Society [published correction appears in J Am Coll Cardiol. 2014 Dec 2;64(21):2305-7]. J Am Coll Cardiol. 2014;64(21):e1-e76.doi:10.1016/j.jacc.2014.03.022

18. Manorenj, S., Barla, S., \& Jawalker, S. (2020). Prevalence, risk factors and clinical profile of patients with cardioembolic stroke in South India: a five-year prospective study. International Journal Of Community Medicine And Public Health, 7(7), 2708-2714. doi:http://dx.doi.org/10.18203/2394-6040.ijcmph20203002

19. Khoo CW, Lip GYH. Clinical outcomes of acute stroke patients with atrial fibrillation. Expert Rev Neurother. 2009;7:371-4.

20. Henninger N, Goddeau RP Jr, Karmarkar A, Helenius J, McManus DD. Atrial Fibrillation Is Associated With a Worse 90-Day Outcome Than Other Cardioembolic Stroke Subtypes. Stroke. 2016;47(6):1486-1492. doi:10.1161/STROKEAHA.116.012865

21. Rahman M, Zaman MM, Islam JY, et al. Prevalence, treatment patterns, and risk factors of hypertension and pre-hypertension among Bangladeshi adults. J Hum Hypertens. 2018;32(5):334-348. doi:10.1038/s41371-017-0018-X

22. Ogunsua AA, Shaikh AY, Ahmed M, McManus DD. Atrial Fibrillation and Hypertension: Mechanistic, Epidemiologic, and Treatment Parallels. Methodist Debakey Cardiovasc J. 2015;11(4):228-234. doi:10.14797/mdcj-11-4-228

23. MacDougall NJJ, Amarasinghe S, Muir KW. Secondary prevention of stroke. Expert Rev Neurother. 2009;7:1103-15. 
medRxiv preprint doi: https://doi.org/10.1101/2022.02.16.22271069; this version posted February 21, 2022. The copyright holder for this preprint

(which was not certified by peer review) is the author/funder, who has granted medRxiv a license to display the preprint in perpetuity.

It is made available under a CC-BY 4.0 International license .

400 24. Hart RG. Cardiogenic embolism to the brain. Lancet. 1992; 339: 589-94.

401 25. Arboix A, Alió J. Cardioembolic stroke: clinical features, specific cardiac disorders and

402 prognosis. Curr Cardiol Rev. 2010;6(3):150-161. doi:10.2174/157340310791658730

403 26. Ferro JM. Brain embolism. Answers to practical questions. J Neurol. 2003;250:139-47

404 27. Hart RG. What causes intracerebral hemorrhage during warfarin therapy? Neurology Oct

405 2000, 55 (7) 907-908; DOI: 10.1212/WNL.55.7.907

406 28. Seiffge DJ, De Marchis GM, Koga M, et al. Ischemic Stroke despite Oral Anticoagulant

407

Therapy in Patients with Atrial Fibrillation [published online ahead of print, 2020 Feb

408 12]. Ann Neurol. 2020;87(5):677-687. doi:10.1002/ana.25700 